\title{
POTENCIAL GEOPARQUE DE UBERABA (MG): GEODIVERSIDADE E GEOCONSERVAÇÃO
}

\section{Geopark potential of Uberaba (MG): geodiversity and geoconservation}

\author{
Letícia Hirata Godoy \\ Doutoranda em Geologia Regional pelo IGCE/UNESP. Bolsista Capes \\ leticiahirata@gmail.com \\ Diego de Souza Sardinha
}

Prof. Adjunto, Instituto de Ciência e Tecnologia, UNIFAL, Alfenas diegosardinha@yahoo.com.br

Reinaldo José Bertini

Prof. Assistente-Doutor, Depto. de Geologia Aplicada, IGCE, UNESP, Rio Claro rbertini@rc.unesp.br

Fabiano Tomazini da Conceição Prof. Adjunto, Deplan, IGCE, UNESP, Rio Claro

Carolina Del Roveri

Profa. Adjunta, Instituto de Ciência e Tecnologia, UNIFAL, Campus Poços de Caldas carolina.roveri@unifal-mg.edu.br

César Augusto Moreira Prof. Assistente-Doutor, Depto. de Geologia Aplicada, IGCE, UNESP, Rio Claro moreirac@rc.unesp.br

Artigo recebido em 25/08/2012 e aceito para publicação em 12/11/2012

Resumo: O município de Uberaba apresenta grande potencialidade geoturística quando considerado aos seus patrimônios geológicos. As rochas ígneas da Formação Serra Geral são encontradas em 12 atrativos geoturísticos, com destaque para as cachoeiras de Ponte Alta (40 metros de altura) e Peirópolis III (sete metros de altura). As rochas sedimentares da Formação Uberaba foram descritas em 11 pontos, destacando-se Cachoeira e Gruta do Giovane (doze metros de altura). Nas rochas sedimentares da Formação Marília destaca-se o afloramento da Caieira (gruta de três metros com estalactites e estalagmites) e a Cachoeira do Vale Encantado (oito metros de altura), entre outros 8 locais. Após o levantamento da geodiversidade foi realizado um diagnóstico ambiental nos potenciais atrativos geoturísticos, sendo utilizado o Método Visitor Impact Management. Os resultados indicam que somente a Cachoeira do Vale Encantado apresenta impacto moderado, o menor quando comparado aos 22 sítios com impacto alto ou preocupante, e 7 com impacto muito alto. Além de definir as estratégias de manejo e monitoramento dos indicadores de impacto ambiental, o presente trabalho serve de base para que as atividades do potencial Geoparque de 
Uberaba (MG) sejam realizadas com responsabilidade ambiental e/ou geoconservação.

Palavras-chaves. Caracterização ambiental. Geoturismo. Diagnóstico ambiental. Responsabilidade ambiental.

Abstract: Uberaba municipality, Western Minas Gerais State, has a great geotouristic potential, regarding its geological heritage. The igneous rocks from Serra Geral Formation are found in 12 points, highlighting Ponte Alta (40 meters) and Peirópolis III (7 meters) waterfalls. The sedimentary rocks from Uberaba Formation were described in 11 points, especially Giovane Cave and Waterfall (12 meters). In Marilia Formation sedimentary rocks, the Caieira outcrop (three-meter cave with stalactites and stalagmites) and Vale Encantado Waterfall (8 meters) can be pointed out, among other 8 spots. After the geodiversity assessment, an environmental diagnosis was conducted throughout the potential geotourism attractions, by using the Visitor Impact Management Method. The results indicate that only Vale Encantado Waterfall presents a moderate impact, the least when compared to 22 other sites, exhibiting high or worrisome impact, and 7 with very high impact. In addition to setting the management strategies, and monitoring the environmental impact indicators, this work provides the basis so that activities in the potential Geopark of Uberaba (MG) can be conducted with environmental responsibility and / or geoconservation.

Key-words: Environmental characterization. Geotourism. Environmental diagnosis. Environmental responsibility.

\section{INTRODUÇÃO}

O geoturismo compreende o segmento do turismo que tem na geodiversidade seu atrativo. Embora atividades de geoturismo ocorram há muito tempo, este termo passou a ser divulgado na Europa apenas em 1995, enquanto no Brasil esta palavra começou a ser mais utilizada ao início dos anos 2000 (NASCIMENTO et al., 2007; VIANA \& NASCIMENTO, 2009). Geoturismo é a atividade do turismo com conotação geocientífica, ou seja, a visita organizada e orientada a locais onde ocorrem recursos do meio físico, que testemunham uma fase do passado ou da história de origem e evolução do Planeta Terra. Também se inclui, neste contexto, o conhecimento científico sobre a gênese da paisagem, processos envolvidos e testemunhos registrados em rochas, solos e relevos (SILVA \& PERINOTTO, 2007).

A United Nations Educational, Scientific and Cultural Organization - UNESCO apresentou, em 2001, a definição de geoparque, como elemento primordial do geoturismo. Trata-se de uma área delimitada, que possua significativas exposições geológicas, paleontológicas ou geomorfológicas, suficientemente grande para o desenvolvimento sustentável, onde exista uma população no seu interior a qual necessariamente deverá ser beneficiada com sua criação
(UNESCO, 2005).

No Brasil, as propostas de criação de geoparques são incentivadas pelo Projeto Geoparques, uma das áreas de atuação do Serviço Geológico do Brasil - CPRM (CAMOZZATO \& SCHOBBENHAUS, 2003). O Departamento de Recursos Minerais do Rio de Janeiro - DRM realiza trabalhos relevantes, no âmbito do Projeto "Caminhos Geológicos" (CAMINHOS GEOLÓGICOS, 2012), que documentou diversas regiões do Rio de Janeiro, propondo geoparques de características diversas.

As Geociências são a base do geoturismo, e por meio da sensibilização do turista se busca a proteção de determinada área por meio da conservação de seus recursos, utilizando para isto a interpretação deste patrimônio, tornando-o acessível ao público leigo, além de promover sua divulgação e desenvolvimento das Ciências da Terra (ROCHA \& NASCIMENTO, 2007). Como todo patrimônio natural, também requer cuidados ambientais de uso e conservação. Neste sentido, o diagnóstico de impactos ambientais em projetos turísticos de atrativos naturais se torna importante para a busca da proteção do meio ambiente por meio da atividade turística, além do equilíbrio entre intensidade e tipologia da atividade, respeitando a capacidade de suporte e a fragilidade do meio.

A partir da década de 1970, muitos métodos 
Potencial Geoparque de Uberaba (MG): geodiversidade e geoconservação Letícia Hirata Godoy, Diego de Souza Sardinha, Reinaldo José Bertini, Fabiano Tomazini da Conceição, Carolina Del Roveri, César

Augusto Moreira

foram utilizados para avaliar e quantificar os impactos provenientes das atividades turísticas relacionadas aos atrativos turísticos naturais de uma região, tais como Limits of Acceptable Change - LAC (STANKEY et al., 1985), Visitor Impact Management - VIM (GRAEFE et al., 1990), Capacidade de Carga (CIFUENTES, 1992), Pressão-Estado-Resposta (OECD, 1994), Visitor Experience and Resource Protection - VERP (NPS, 1997). No Brasil, o Método de Capacidade de Carga é o mais utilizado e representa o máximo de pessoas que um ambiente pode suportar, sem alterar a qualidade ambiental e da experiência da visita (WEARING \& NEIL, 2001).

Com a evolução dos estudos de impacto ambiental, o Método VIM é o que possibilita o trabalho mais adequado para o propósito deste estudo, sendo utilizado em estudos nos parques nacionais do Iguaçú (PR) e Itatiaia (RJ/MG/SP), no Parque Estadual Intervales (SP) (MAGRO 1999, 2001). Foi utilizado também em uma propriedade particular em Brotas (SP) (FREIXEDAS-VIEIRA et al., 2000), nos atrativos turísticos naturais dos municípios de Altinópolis (SARDINHA et al., 2007) e Rifaina (ZANFELICE et al., 2009).

O inventário da geodiversidade de um local, e a seleção de sítios representativos da sua história evolutiva, são os primeiros passos para a determinação do patrimônio geológico (minerais, rochas e fósseis), geomorfológico (formas de relevo e seus processos) e pedológico (solos e outros depósitos superficiais), que por sua vez, formam a base para a geoconservação e geoturismo. O município de Uberaba apresenta grande potencialidade em relação aos seus atrativos geoturísticos, com paisagens dotadas de rios, cachoeiras, grutas, planaltos, mesas, campos, vales, o que permite uma nova modalidade de turismo na região.

\section{OBJETIVO}

O objetivo deste trabalho consiste em caracterizar o potencial geoparque (geodiversidade) e identificar os impactos ambientais (geoconservação) dos potenciais atrativos geoturísticos do município de Uberaba - MG. Os conhecimentos gerados podem fornecer subsídios necessários para ações voltadas ao planejamento geoturístico, diminuição da degradação ambiental e gerenciamento integrado do potencial geoparque como alternativa econômica sustentável para o município.

\section{ASPECTOS GERAIS DO MUNICÍPIO DE UBE- RABA}

Uberaba está localizada na região do Triângulo Mineiro, estado de Minas Gerais, entre as coordenadas $19^{\circ} 55^{\prime}$ 'de latitude Sul e $48^{\circ} 50^{\prime}$ de longitude Oeste. O município ocupa uma área de aproximadamente 4.424 $\mathrm{km}^{2}$ e possui uma população de 296.000 habitantes, estando entre as oito maiores cidades do estado (IBGE, 2011). A captação superficial de água, para o abastecimento público, é quase na sua totalidade feita através do rio Uberaba. Mais de $98 \%$ da área urbanizada do município é atendida por rede coletora de esgoto, destes $76 \%$ são tratados através da ETE Capim (2 \%) e da ETE Francisco Velludo / Rio Uberaba (74 \%) (PMU, 2009).

A vegetação original era constituída por cerrado, cerradão e campo cerrado, restritas a reservas particulares e a faixas descontínuas às margens dos cursos de água. Pastagens espalham-se por grande área do município, e culturas em desenvolvimento e avançadas também fazem parte da paisagem (VALE JUNIOR, 2008).

Segundo o sistema de Köppen, Uberaba está submetida a um clima tropical chuvoso do tipo AW, ou seja, de inverno seco e verão úmido. As estações são bem definidas, apresentando climas frio e seco durante o inverno e quente e úmido durante o verão. A precipitação média anual varia entre $1300 \mathrm{~mm}$ e $1600 \mathrm{~mm}$. O regime pluviométrico é caracterizado por um período chuvoso de outubro até março, com precipitação média de $180 \mathrm{~mm}$, sendo setembro, abril e maio meses de transição, com precipitação média de $90 \mathrm{~mm}$. Os meses de junho, julho e agosto os mais secos, com precipitação média de 30 mm (PMU, 2009).

O município de Uberaba faz parte da unidade de relevo dos Planaltos e Chapadas da Bacia Sedimentar do Paraná, estando inserida na sub-unidade Planalto Setentrional da Bacia do Paraná (RADAM BRASIL, 1983). A topografia é caracterizada por superfícies planas ou ligeiramente onduladas, formada por rochas ígneas e sedimentares do período Cretáceo 
Potencial Geoparque de Uberaba (MG): geodiversidade e geoconservação

Letícia Hirata Godoy, Diego de Souza Sardinha, Reinaldo José Bertini, Fabiano Tomazini da Conceição, Carolina Del Roveri, César

Augusto Moreira

(145,5 a 65,5 m.a.). Possui relevo medianamente dissecado e apresenta topos nivelados entre $750 \mathrm{~m}$ e $900 \mathrm{~m}$ (MACHADO \& SILVA, 2010). A maioria dos solos apresenta textura média, variando de arenoso a argiloso e são classificados de forma geral como latossolos de diferentes graus de fertilidade, com predominância do Latossolo Vermelho Distroférrico, e Latossolo Vermelho Distrófico Típico (MACHADO \& SILVA, 2010).

Quanto à Geologia ocorrem na área do município de Uberaba as unidades da Bacia do Paraná pertencentes ao Grupo São Bento (formações Botucatu e Serra Geral) e ao Grupo Bauru (formações Uberaba, Adamantina e Marília). A Formação Botucatu (203,6 a 145,5 m.a.) estende-se inferiormente a frente das cuestas por toda a faixa de afloramento da Formação Serra Geral, e é constituída por arenitos de granulação fina a média, com bom arredondamento, apresentando acamamento plano-paralelo e estratificação cruzada planar (SOARES \& LANDIM, 1974). As rochas eruptivas da Formação Serra Geral (145,5 a 130,0 m.a.) constituem um conjunto de derrames de basaltos toleíticos de espessura individual bastante variável, sendo constituídos por rochas de colorações cinza escura a negra (SQUISATO et al., 2009). A Formação Adamantina (93,5 a 85,8 m.a.) é constituída por arenitos estratificados de colorações rosada a marrom e granulação fina, intercalados a lamitos arenosos maciços (SOARES et al., 1980). A Formação Uberaba (89,3 a 83,5 m.a.) é formada por arenitos muito finos a lamitos siltosos, arenitos finos subordinados, com matriz argilosa, incluindo grande quantidade de materiais de retrabalhamento de rochas ígneas efusivas e intrusivas básicas, ultrabásicas e intermediárias, alcalinas ou não (HASUI, 1968). A Formação Marília (70,6 a 65,5 m.a.) é divida nos membros Ponte Alta e Serra da Galga na região do Triângulo Mineiro, sendo o primeiro constituído essencialmente por calcários e o segundo por arenitos e lamitos arenosos (FERNANDES \& COIMBRA, 2000).

\section{MATERIAIS E MÉTODOS}

O levantamento de campo foi realizado utilizando uma planilha, com características geológicas (tipo de afloramento, condições, descri- ção, litologia, composição, trama, cor, estruturas) e pedológicas (cor, textura, estruturas, consistência). Foram identificados e descritos 30 atrativos geoturísticos, com a tomada de coordenadas geográficas (GPS Garmin e Trex Vista HCx) e direção e rumo (Bússola Brunton Geo Pocket Transit). A origem e evolução do local (gênese da paisagem), o acesso ao público e possíveis associações com as atividades de ecoturismo foram os principais critérios utilizados para a escolha dos 30 atrativos geoturísticos.

Para avaliação e quantificação dos impactos ambientais foi utilizado o Método Visitor Impact Management - VIM (GRAEFE et al., 1990). Sua ênfase está na identificação das relações entre os principais indicadores dos impactos, assim como dos padrões de uso das visitações das áreas naturais (SARDINHA et al., 2007).

A abordagem metodológica foi desenvolvida em oito etapas (Figura 1). As duas primeiras consistiram em levantar e revisar as informações e objetivos do uso atual dos atrativos geoturísticos de Uberaba (MG). Na terceira etapa foram selecionados indicadores, buscando a identificação de problemas relevantes, assim como os fatores que refletiam os impactos no ambiente analisado. $\mathrm{Na}$ quarta etapa foi criado um índice de análise ambiental simplificado (Quadro 1), com pesos para os impactos que possam afetar o recurso geoturístico em diversos graus de intensidade. Após o preenchimento foram somados os pontos de cada questão (mínimo zero e máximo trinta), no qual quanto maior a pontuação menor o nível de impacto no atrativo estudado. De 30 a 25 pontos há mínima ou pouca presença de impacto, de 24 a 18 moderada presença de impacto, de 17 a 10 pontos o impacto é alto ou preocupante, menor ou igual a 9 presença muito alta de impacto.

Soc. \& Nat., Uberlândia, 25 (2): 395-410, mai/ago/2013 
Figura 1. Etapas do processo de planejamento para a aplicação do índice de análise ambiental simplificado

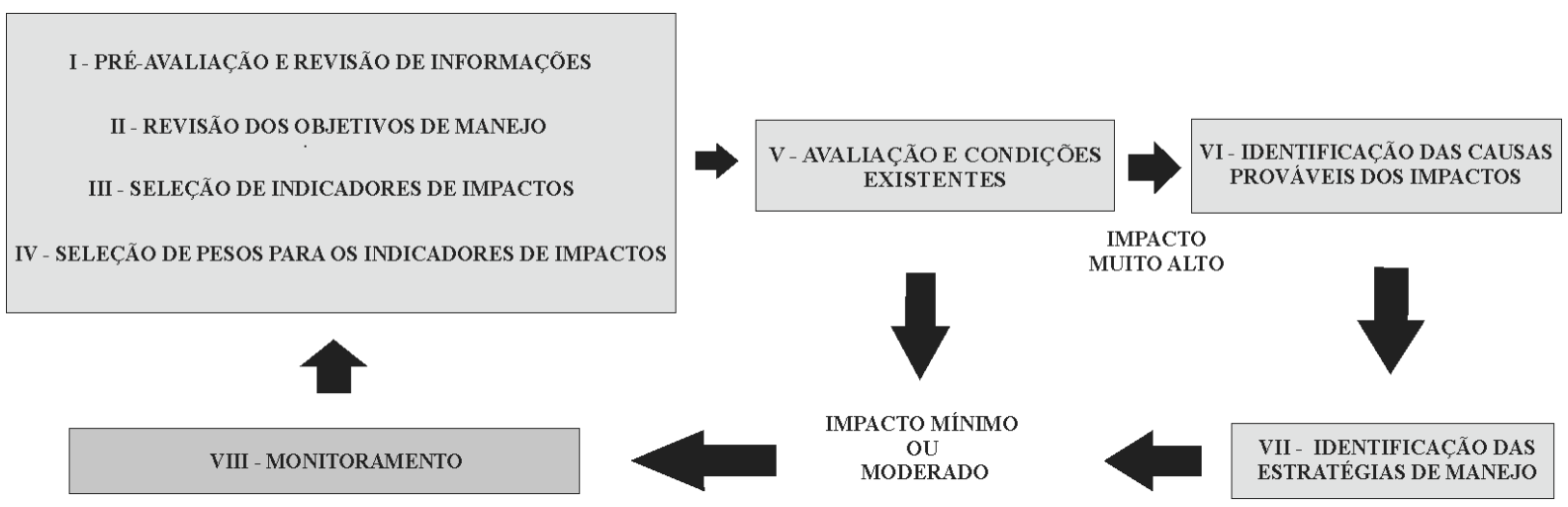

Fonte: Modificado de Sardinha et al. (2007).

A quinta etapa consistiu na avaliação de campo através do preenchimento da planilha (Quadro 1). As etapas seis e sete permitiram avaliar as causas, estabelecendo estratégias de manejo para as áreas analisadas, sendo para isto adotado o modelo de Pressão-
-Estado-Resposta (OECD, 1994). Finalmente na etapa oito foi abordado o monitoramento dos indicadores de impacto, fornecendo os dados para uma avaliação contínua de ações de manejo a serem implantadas nos potenciais atrativos geoturísticos.

Quadro 1. Modelo da planilha aplicada em campo com possíveis indicadores de impactos

\begin{tabular}{|c|c|c|c|}
\hline Indicadores biofísicos & Peso & Indicadores biofísicos & Peso \\
\hline Cobertura vegetal no entorno & & Erosão no entorno & \\
\hline Sem vegetação & $(0)$ & Boçoroca & $(0)$ \\
\hline Com vegetação rasteira & (1) & Ravina & (1) \\
\hline Com vegetação arbustiva & ( 2 ) & Sulco & (2) \\
\hline Com vegetação arbórea & $(3)$ & Sem erosão & $(3)$ \\
\hline Fauna no entorno & & Riscos associados à saúde & \\
\hline Ausência de animais nativos & $(0)$ & Escorregar / ferimento fatal & $(0)$ \\
\hline Pouca presença de animais nativos & (1) & Escorregar / ferimento traumático & (1) \\
\hline Moderada presença de animais nativos & (2) & Escorregar / ferimento leve & ( 2 ) \\
\hline Grande presença de animais nativos & (3) & Sem risco associado & $(3)$ \\
\hline Lixo no entorno & & Som / ruídos & \\
\hline Muito lixo & $(0)$ & Grande quantidade & $(0)$ \\
\hline Pouco lixo & (1) & Média quantidade & (1) \\
\hline Lixo em latões & $(2)$ & Pequena quantidade & $(2)$ \\
\hline Sem lixo & $(3)$ & Sem problemas & $(3)$ \\
\hline Saneamento & & Danos ao atrativo & \\
\hline Esgoto & $(0)$ & Vandalismo & $(0)$ \\
\hline $\begin{array}{l}\text { Fossa } \\
\text { Dejetos ou urina }\end{array}$ & $(1)$ & $\begin{array}{l}\text { Danos no entorno } \\
\text { Inscricões }\end{array}$ & $\left(\begin{array}{l}1 \\
2\end{array}\right)$ \\
\hline $\begin{array}{l}\text { Dejetos ou urina } \\
\text { Ausente }\end{array}$ & $\left(\begin{array}{l}2 \\
3\end{array}\right)$ & $\begin{array}{c}\text { Inscrições em rocha / vegetação } \\
\text { Sem danos }\end{array}$ & $\left(\begin{array}{l}2 \\
3\end{array}\right)$ \\
\hline Acesso & & Queda de blocos & \\
\hline Muito difícil & $(0)$ & Alto & $(0)$ \\
\hline Difícil & $(1)$ & Médio & $(1)$ \\
\hline $\begin{array}{l}\text { Moderado } \\
\text { Fácil }\end{array}$ & $(3)$ & $\begin{array}{l}\text { Pequeno } \\
\text { Sem risco }\end{array}$ & 3 \\
\hline
\end{tabular}

Fonte: Modificado de SARDINHA et al., 2007. 
Potencial Geoparque de Uberaba (MG): geodiversidade e geoconservação

Letícia Hirata Godoy, Diego de Souza Sardinha, Reinaldo José Bertini, Fabiano Tomazini da Conceição, Carolina Del Roveri, César Augusto Moreira

\section{RESULTADOS E DISCUSSÕES}

\section{Geodiversidade - Caracterização do Pontencial Geoparque de Uberaba (MG)}

A figura 2 apresenta os 30 atrativos geoturísticos descritos e identificados no levantamento de campo, visando à caracterização do potencial geoparque do município de Uberaba (MG). As rochas da Formação Serra Geral (Cretáceo Inferior - 145,5 a 130,0 m.a. $-K_{1 \beta s g}$ ) foram descritas e identificadas em doze pontos, sendo: cinco cachoeiras $(\mathrm{C}=6,7$, 18, 21 e 22); dois cortes em avenidas $(\mathrm{Ca}=10$ e 12); uma pedreira abandonada $(\mathrm{Pa}=20)$; um leito de rio, soleira $(\mathrm{L}=24)$; e três cortes em rodovias $(\mathrm{Cr}=28$, 29 e 30) conforme a figura 2.

As cachoeiras de Ponte Alta (6), com 40 metros de altura (Figura 3a), e Peirópolis III (22), com 7 metros de altura (Figura 3b), se destacam entre as demais, pois ambas apresentam contatos com arenitos da Formação Botucatu (Jurássico - 203,6 a 145,5 m.a.) metamorfisados ("hornfels"), localizados na base das cachoeiras (com dobras convolutas), diabásio da Formação Serra Geral (145,5 a 130,0 m.a.) com juntas e fraturas horizontais e verticais sucedendo o contato logo acima, e basaltos da Formação Serra Geral (145,5 a 130,0 m.a.) escuros com disjunção colunar no topo. Outro destaque é a Cachoeira Peirópolis II (C =21), com 6 metros de altura (Figura 3c), constituída por basaltos da Formação Serra Geral (145,5 a 130,0 m.a.), maciços, de coloração escura, com grande quantidade de juntas e fraturas (disjunção colunar). Neste local o solo possui coloração vermelha escura, textura argilosa, estrutura colunar e consistência seca.

Figura 2. Mapa geológico com os 30 atrativos geoturísticos descritos e identificados no levantamento de campo visando à caracterização do potencial geoparque.

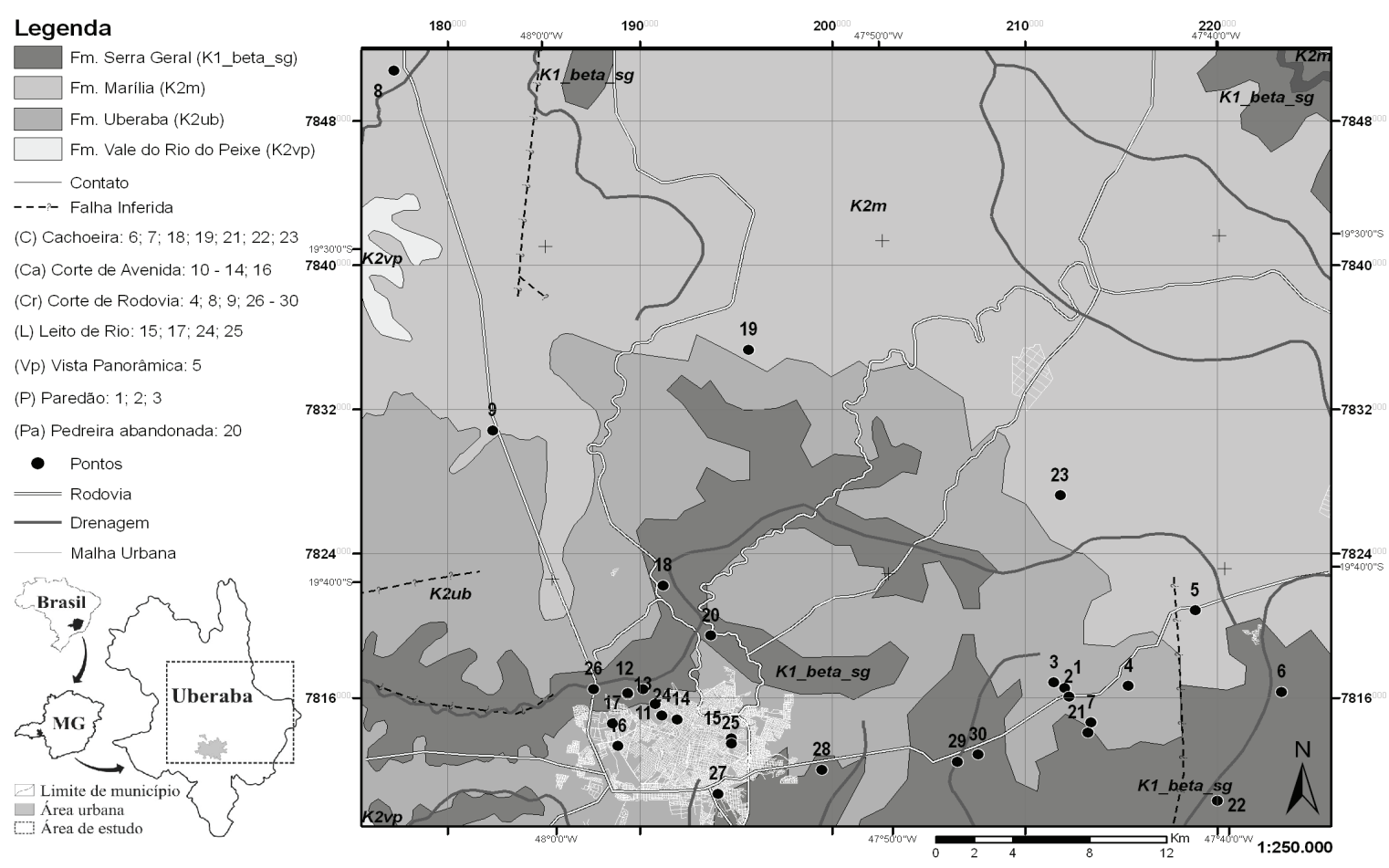

Elaboração dos autores. 
Cachoeiras com quedas menores também foram identificadas, no Rio Uberaba a Cachoeira de Léia $(\mathrm{C}=18)$, com aproximadamente 3 metros de altura, formada por basaltos maciços de cor escura com juntas e fraturas. A presença de aluvião com grande quantidade de areias, cascalhos e calhaus, também pode ser visualizada neste afloramento. A cachoeira localizada no Bairro de Peirópolis, Cachoeira de Peirópolis I (C =7), com 2 metros de altura é, formada por basaltos maciços escuros da Formação Serra Geral (145,5 a 130,0 m.a.), com fraturas horizontais e verticais. Ambas possuem solos com coloração vermelha, textura argilosa, estrutura granular e consistência úmida. Corredeiras com pequenas quedas de água sobre soleiras, no Córrego das Lajes $(\mathrm{L}=24)$, foram descritas na área urbana de Uberaba e são representadas por basaltos da Formação Serra Geral (145,5 a 130,0 m.a.) com fraturas, juntas e falhas, de coloração acinzentada, sendo que nas margens é possível observar o solo com cores amareladas (ocre), textura argilosa, estrutura angular e consistência úmida.
Afloramentos em cortes de avenidas / rodovia também foram descritos, com destaque para um dique de aproximadamente 2 metros de largura e 3 metros de altura, na BR $262(\mathrm{Cr}=30)$, próximo a Peirópolis (Figura 3d), constituído por diabásio da Formação Serra Geral (145,5 a 130,0 m.a.) maciço na base e no topo, com interfaces marcadas pela presença de vesículas, formadas por gases que ficaram aprisionados durante o resfriamento do magma, e nódulos de coloração esverdeada ou amígdalas, geralmente preenchidas por argilominerais, carbonatos, zeólitas e / ou óxidos de ferro, indicativas de topo de derrame. Na Avenida Rondolfo Borges Junior $(\mathrm{Ca}=12)$ também foi descrito um afloramento de basalto da Formação Serra Geral (145,5 a 130,0 m.a.), maciço, com várias cavidades ou vesículas, e nódulos de coloração esverdeada ou amígdalas. Feições de atuação intempérica (esfoliação esferoidal) também foram descritas nos dois pontos analisados acima.

Figura 3. Pontos analisados e descritos na caracterização do pontencial Geoparque de Uberaba (MG). a) Cachoeira de Ponte Alta (6).

b) Cachoeira Peirópolis III (22). c) Cachoeira Peirópolis II (21). d) Dique de diabásio (30).
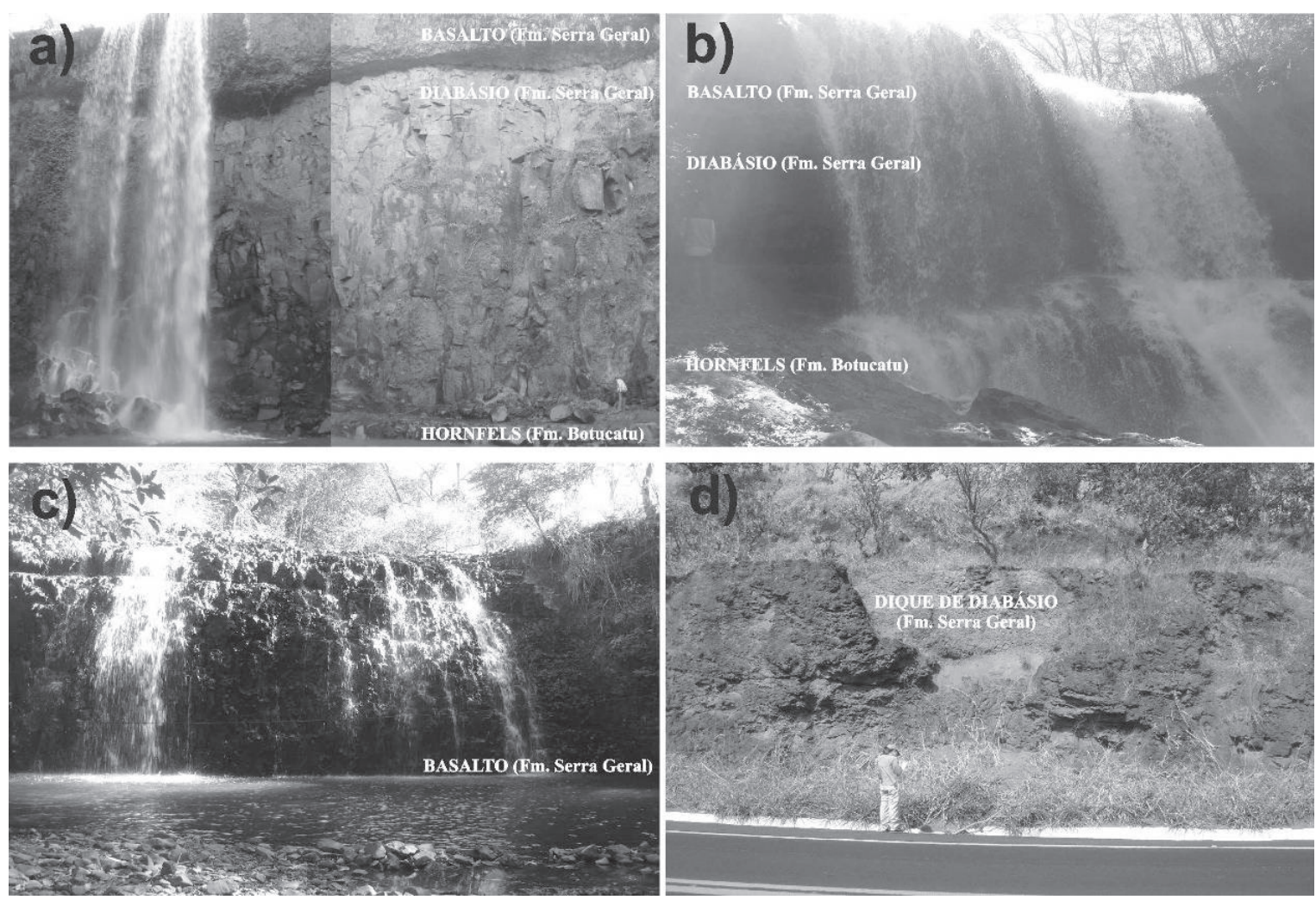

Fonte: Trabalho de campo. Fotos dos autores. 
As rochas da Formação Uberaba (Cretáceo Superior - 89,3 a 83,5 m.a.- $K_{2 U B}$ ) foram descritas em onze pontos, Cachoeira e Gruta do Giovane $(\mathrm{C}=23)$, leito de rio / represa $(\mathrm{L}=15,17$ e 25$)$, corte de avenida $(\mathrm{Ca}=10,11,13,14$ e 16$)$ e corte de rodovia $(\mathrm{Cr}=$ 26 e 27). A Cachoeira e Gruta do Giovane $(\mathrm{C}=23)$, localizada aproximadamente $25 \mathrm{~km}$ a Leste do centro de Uberaba (MG), possui um salão com 12 metros de altura, constituído por arenitos maciços a estratificados com colorações avermelhada e esverdeada na base (Formação Uberaba - 89,3 a 83,5 m.a.), e arenitos com cimentação carbonática de coloração branca no topo (Formação Marília - 70,6 a 65,5 m.a. - Membro Ponte Alta).

No Parque das Acácias (Piscinão) foram descritos dois afloramentos (15 e 25), ambos constituídos por arenitos da Formação Uberaba (89,3 a 83,5 m.a.). A camada basal é formada por siltitos esbranquiçados (creme), seguidos por uma lâmina $(10 \mathrm{~cm}$ de espessura) de siltito argiloso avermelhado (estratificação cruzada planar), em contato abrupto com uma camada de arenito conglomerático verde maciço e silicificado, com granodecrescência ascendente, sendo que os grãos são mal selecionados e predominantemente angulosos a sub-angulosos.
O afloramento do ponto $(\mathrm{L}=17)$ está localizado nas margens do Córrego da Saudade, no Distrito Industrial de Uberaba (MG), onde foram encontrados fósseis de uma preguiça gigante. Neste local foram identificadas camadas de siltitos / argilitos, com coloração branca a rósea na base, seguidas por camadas de arenitos esverdeados conglomeráticos, cobertas no topo por uma camada de aluvião e turfas, com fragmentos da Formação Uberaba (89,3 a 83,5 m.a.). Um solo com coloração preta e textura argilosa também foi descrito neste local.

Quanto aos afloramentos de cortes de rodovia / avenida (Ca e Cr) da Formação Uberaba (89,3 a 83,5 m.a.), analisados neste trabalho, destaca-se o da Avenida Nenê Sabino (Figura 4a) ou Viaduto Bairro Beija-Flor $(\mathrm{Ca}=16)$. Na base há um pacote de aproximadamente 3 metros de espessura de arenito fino bem selecionado, apresentando estratificação cruzada acanalada, gerada pela colmatação de pequenos canais fluviais ou de erosão, seguido por pacotes intercalados de materiais grossos e finos, arenitos finos e siltitos arenosos. No topo há pacotes maciços de arenitos com interdigitação de aproximadamente 2 metros. Na borda do afloramento foram observadas grandes quantidades de clastos (pedregulhos), indicativos de um provável paleocanal.

Figura 4. a) Viaduto Bairro Beija-Flor (16). b) Rodovia BR 050 (26). c) Base da Caieira (1). d) Cachoeira do Vale Encantado (19). e) Ponto 2 de Price (3).

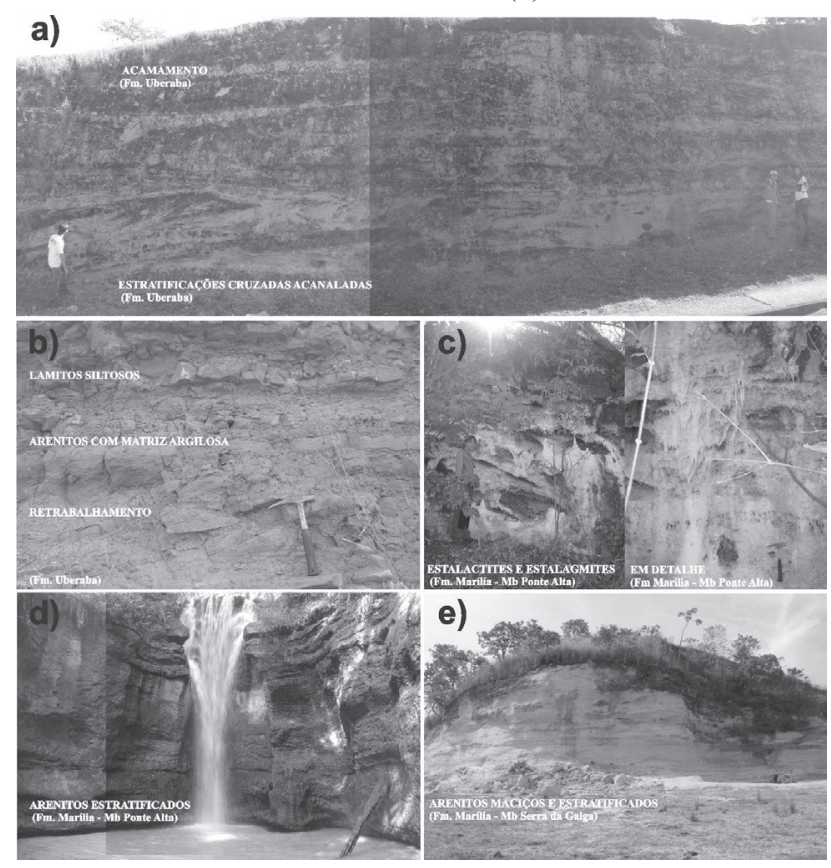

Fonte: Trabalho de campo. Fotos dos autores. 
Potencial Geoparque de Uberaba (MG): geodiversidade e geoconservação Letícia Hirata Godoy, Diego de Souza Sardinha, Reinaldo José Bertini, Fabiano Tomazini da Conceição, Carolina Del Roveri, César

Augusto Moreira

Também são destaques da Formação Uberaba (89,3 a 83,5 m.a.) neste estudo o afloramento da Rodovia $\mathrm{BR} 050(\mathrm{Cr}=26)$, constituído de lamitos siltosos avermelhados, arenitos finos subordinados com matriz argilosa, incluindo grande quantidade de materiais de retrabalhamento (Figura 4b). E o afloramento na Av. Rondolfo Borges Junior $(\mathrm{Ca}=13)$, constituído de arenitos vermelhos maciços com matriz siltosa na base e uma sucessão de arenitos esverdeados finos homogêneos à conglomeráticos com granocrescência ascendente (seixos polimíticos angulares a arredondados) e estratificações cruzadas de baixo ângulo.

Os membros Ponte Alta e Serra da Galga, pertencentes à Formação Marília (70,6 a 65,5 m.a.), são subdivisões restritas ao Triângulo Mineiro. O primeiro é basal, constituído essencialmente por calcários de colorações creme a esbranquiçada, com nódulos de cimentação carbonática, pouco a bastante intemperizados, conforme observados nos afloramentos $(\mathrm{P}=$ 1) base da Caieira, exibindo alteração do calcário e formação de gruta com estalactites e estalagmites em provável zona de fratura (Figura 4c). Também foram descritos e analisados os afloramentos na Rodovia BR $262(\mathrm{Cr}=4)$, composto por calcarenito escuro e acizentado, maciço a nodular, e calcretes, e na BR $050(\mathrm{Cr}$ $=8$ ), mostrando calcário maciço de coloração creme.

A Cachoeira do Vale Encantado $(C=19)$ está localizada $30 \mathrm{~km}$ ao Norte do centro do Município de Uberaba, às margens do Córrego da Mata, dentro da Reserva Particular do Patrimônio Nacional (RPPN Vale Encantado), uma floresta de 38,13 hectares. A cachoeira apresenta uma queda de 8 metros e é constituída por calcarenitos do Membro Ponte Alta, de colorações escura, acizentada e rosada, de granulação fina, intercalados a lamitos arenosos maciços (Figura 4d). No local foi possível identificar grande quantidade de areia (aluvião) na base da cachoeira e solos de coloração acinzentada, textura arenosa, estrutura granular e consistência úmida.

O Membro Serra da Galga ocorre no corte da Rodovia BR $050(\mathrm{Cr}=9)$, e em dois pontos em uma fazenda próxima à Peirópolis, afloramentos conhecidos na região como Ponto 1 de Price $(\mathrm{P}=2) \mathrm{e}$ Ponto 2 de Price $(\mathrm{P}=3)$ (Figura 4e), e fazem parte do importante sítio paleontológico descoberto em 1945 pelo paleontólogo Llewellyn Ivor Price, do Departa- mento Nacional da Produção Mineral - DNPM onde, atualmente, encontram-se depositados grande parte de seus achados (CPRM, 2012). Nestes locais as rochas são constituídas por sucessões de arenitos maciços a estratificados, localmente conglomeráticos, com grãos arredondados a angulosos e lamitos arenosos, de colorações creme a branca, com conteúdo paleontológico diversificado.

Por fim, o ponto localizado no auto posto Bela Vista $(\mathrm{Vp}=5)$, trata-se de uma panorâmica da geomorfologia local, permitindo a observação da ruptura no modelado provocada pela presença de cuestas (basaltos da Formação Serra Geral - 145,5 a 130,0 m.a.), recobertas em discordância angular pelas formações que constituem o Grupo Bauru, neste local representado pela Formação Marília (70,6 a 65,5 m.a.), que conferem à região um relevo de serras tabulares (chapadas).

\section{GEOCONSERVAÇÃO - AVALIAÇÃO E QUAN- TIFICAÇÃO DOS IMPACTOS AMBIENTAIS}

O quadro 2 apresenta as porcentagens de indicadores biofísicos de impactos avaliados nos pontos de estudo de acordo com o tipo de atrativo e a figura 5 o percentual de impacto ambiental para cada grupo de atrativo, de acordo com os resultados obtidos a partir do índice de análise ambiental simplificado aplicado aos 30 atrativos geoturísticos descritos e identificados em Uberaba (MG).

Os resultados indicaram os locais que apresentaram presença muito alta de impacto. Nos afloramentos (2) e (3), pontos 1 e 2 de Price respectivamente, a falta de cobertura vegetal, fauna, impactos sonoros, lixo, erosão, queda de blocos, fazem parte da paisagem, sendo que neste local, por muitos anos, foram realizadas prospecções paleontológicas sem qualquer estudo de impacto ambiental, controle, fiscalização ou acompanhamento profissional, fatos que aceleraram um processo avançado de erosão, gerando voçorocas ativas que atingem até $10 \mathrm{~m}$ de comprimento e $6 \mathrm{~m}$ de profundidade, de acordo com observações em campo (figuras 6a e 6b). 
Potencial Geoparque de Uberaba (MG): geodiversidade e geoconservação

Letícia Hirata Godoy, Diego de Souza Sardinha, Reinaldo José Bertini, Fabiano Tomazini da Conceição, Carolina Del Roveri, César Augusto Moreira

Quadro 2. Percentual de cada atrativo geoturístico de Uberaba que apresenta os indicadores biofísicos dos pontos analisados.

\begin{tabular}{|c|c|c|c|c|c|c|c|c|c|c|c|c|c|c|c|c|c|c|c|c|}
\hline \multirow{2}{*}{ 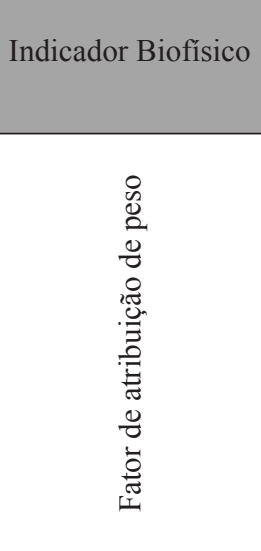 } & \multicolumn{4}{|c|}{$\begin{array}{l}\text { Cobertura vegetal no } \\
\text { entorno }\end{array}$} & \multicolumn{4}{|c|}{ Erosão no entorno } & \multicolumn{4}{|c|}{ Fauna no entorno } & \multicolumn{4}{|c|}{$\begin{array}{l}\text { Riscos associados } \\
\text { à saúde }\end{array}$} & \multicolumn{4}{|c|}{ Lixo no entorno } \\
\hline & 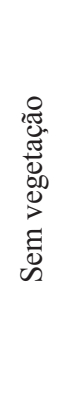 & 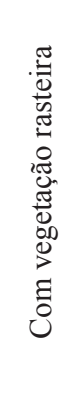 & 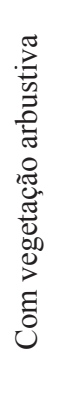 & 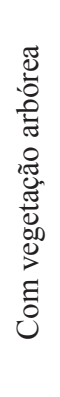 & $\begin{array}{l}\text { ర্ } \\
0 \\
0 \\
0 \\
0\end{array}$ & $\underset{\widetilde{\pi}}{\stackrel{\pi}{\Xi}}$ & $\frac{8}{\bar{E}}$ & 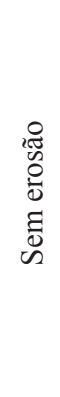 & $\begin{array}{l}\frac{\pi}{0} \\
\frac{\Xi}{8} \\
\stackrel{\Xi}{Z}\end{array}$ & 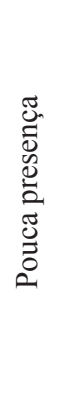 & 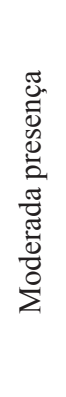 & 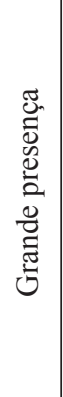 & 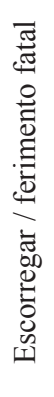 & 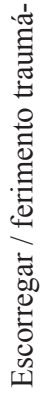 & 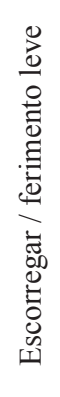 & 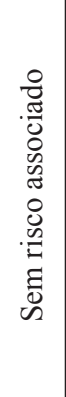 & 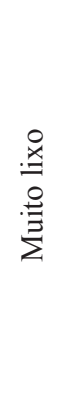 & 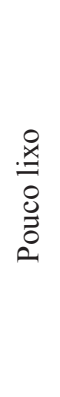 & 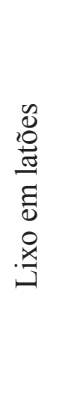 & 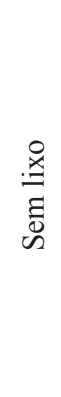 \\
\hline Atrativo & \multicolumn{20}{|c|}{ Porcentagem } \\
\hline Cachoeira & - & - & 14 & 86 & - & 14 & 29 & 57 & 14 & 57 & 29 & - & 14 & 14 & 72 & - & 29 & 57 & - & 14 \\
\hline Leito de Rio & - & 75 & 25 & - & - & 25 & - & 75 & 25 & 75 & - & - & - & - & 75 & 25 & 50 & 25 & 25 & - \\
\hline Corte de Avenida & 17 & 83 & - & - & - & - & 17 & 83 & 67 & 33 & - & - & - & - & - & 100 & 17 & 50 & 17 & 17 \\
\hline Corte de Rodovia & - & 74 & 13 & 13 & - & - & 12 & 88 & 75 & 25 & - & - & 13 & 13 & 74 & - & 25 & 63 & - & 12 \\
\hline Pedreira & 100 & - & - & - & - & - & - & 100 & 100 & - & - & - & - & - & 100 & - & 100 & - & - & - \\
\hline Paredão & - & 67 & 33 & - & 67 & - & 33 & - & - & 100 & - & - & - & 67 & 33 & - & - & 33 & - & 67 \\
\hline Vista Panorâmica & - & 100 & - & - & - & - & 100 & - & - & 100 & - & - & - & - & 100 & - & - & 100 & - & - \\
\hline Indicador Biofísico & \multicolumn{4}{|c|}{ Som / ruídos } & \multicolumn{4}{|c|}{ Saneamento } & \multicolumn{4}{|c|}{ Danos ao atrativo } & \multicolumn{4}{|c|}{ Acesso } & \multicolumn{4}{|c|}{ Queda de blocos } \\
\hline 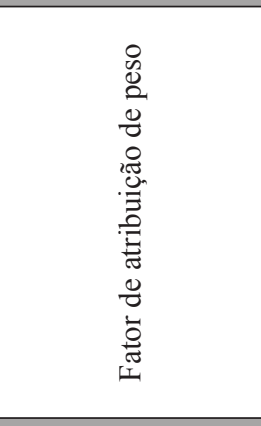 & 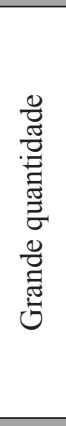 & 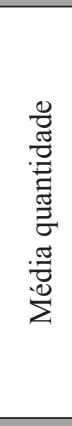 & 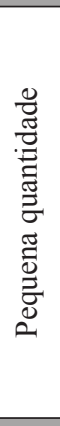 & 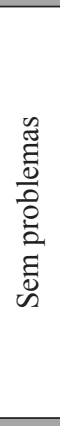 & $\begin{array}{l}0 \\
0 \\
000 \\
010 \\
\text { 뙤 }\end{array}$ & $\begin{array}{l}\text { व } \\
\text { o } \\
0 \\
0\end{array}$ & 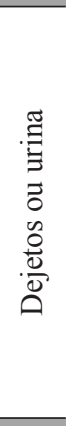 & 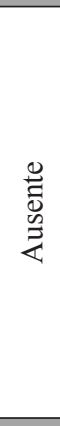 & 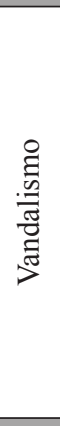 & 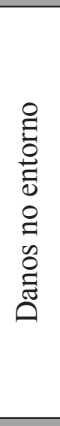 & 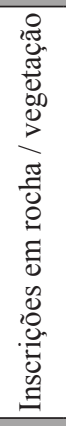 & $\begin{array}{c}\infty \\
0 \\
\tilde{\Xi} \\
\tilde{\Xi} \\
\tilde{D} \\
\tilde{n}\end{array}$ & 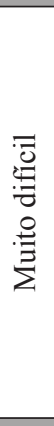 & 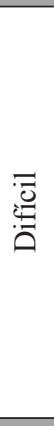 & $\begin{array}{l}\frac{0}{0} \\
\frac{\pi}{0} \\
\frac{0}{0} \\
\sum\end{array}$ & 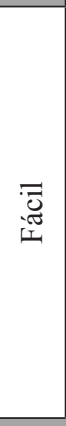 & $\stackrel{\circ}{\stackrel{2}{\gtrless}}$ & $\frac{\circ}{i}$ & $\begin{array}{l}\stackrel{O}{0} \\
\stackrel{0}{0} \\
\stackrel{0}{0}\end{array}$ & 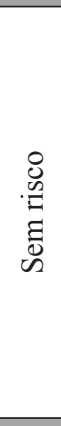 \\
\hline Atrativo & \multicolumn{20}{|c|}{ Porcentagem } \\
\hline Cachoeira & - & 14 & 14 & 72 & - & - & 29 & 71 & 14 & - & 43 & 43 & 29 & - & 29 & 43 & 14 & 14 & 43 & 29 \\
\hline Leito de Rio & 25 & 25 & 25 & 25 & 50 & - & - & 50 & - & - & - & 100 & - & - & 25 & 75 & 25 & - & - & 75 \\
\hline Corte de Avenida & 17 & 17 & 67 & - & - & - & 33 & 67 & - & - & 33 & 67 & - & - & - & 100 & 17 & 50 & 17 & 17 \\
\hline Corte de Rodovia & 100 & - & - & - & - & - & - & 100 & - & - & 12 & 88 & - & - & 25 & 75 & 25 & 13 & 50 & 13 \\
\hline Pedreira & - & 100 & - & - & 100 & - & - & - & - & - & 100 & - & - & - & - & 100 & - & 100 & - & - \\
\hline Paredão & - & - & 33 & 67 & - & - & 33 & 67 & - & 67 & - & 33 & 33 & 67 & - & - & 33 & 33 & 33 & - \\
\hline Vista Panorâmica & - & 100 & - & - & - & - & 100 & - & - & - & - & 100 & - & - & - & 100 & - & - & - & 100 \\
\hline
\end{tabular}

Elaboração dos autores.

Soc. \& Nat., Uberlândia, 25 (2): 395-410, mai/ago/2013 
No afloramento (6) Cachoeira de Ponte Alta, os principais impactos observados foram a grande quantidade de lixo, com latas de alumínio, embalagens, restos alimentares, ausência de saneamento, por conta da presença de restos de excrementos humanos, erosão devido à trilha para descida no atrativo, queda de blocos e falta de cobertura vegetal. No afloramento (13) Avenida Randolfo Borges Júnior, área urbana de Uberaba, lixos, queda de blocos, através de arenitos conglomeráticos com muitas fraturas, impactos sonoros pelo movimento de automóveis, odores desagradáveis, vindos do esgoto do Córrego do Lajeado, foram os principais impactos verificados (Figura 6c).

Figura 5. Percentual de impacto ambiental para cada grupo de atrativos geoturísticos descritos e avaliados em Uberaba (MG).

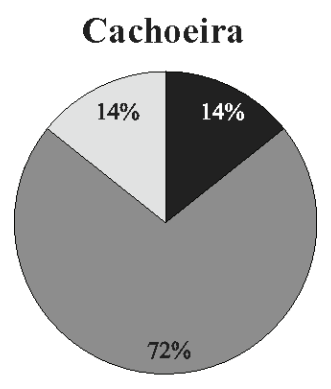

Corte de Avenida

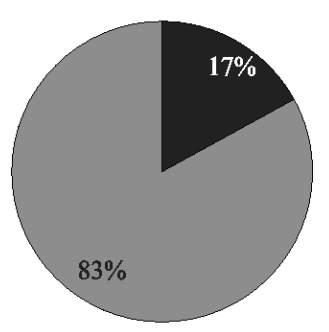

Corte de Rodovia
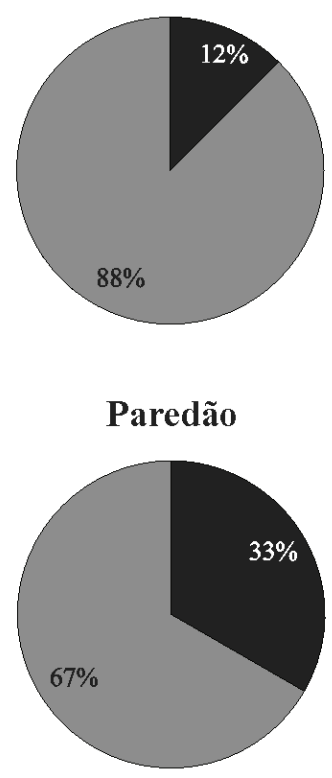

Leito de Rio

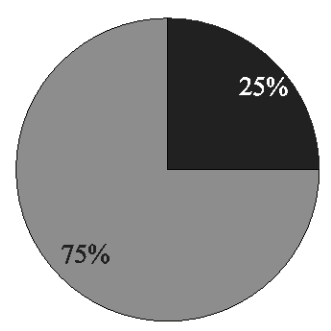

Pedreira + Vista panorâmica

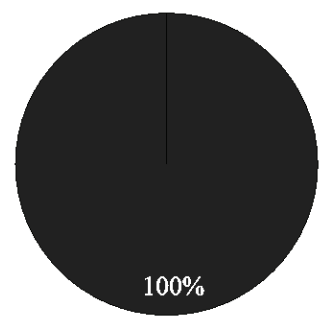

Moderado

Elaboração dos autores.

Na Formação Uberaba, e depósitos fluviais do Quaternário no Córrego da Saudade, afloramento (17), foram observadas margens pisoteadas por gado, área sem mata ciliar, destacando também um barranco instável com risco de desmoronamento, odores desagradáveis vindos de esgotos, lixos e entulhos no entorno do recurso. No afloramento (20) Pedreira de Léia abandonada, localizada aproximadamente $10 \mathrm{~km}$ de centro de Uberaba, foi possível verificar a falta de cobertura vegetal, fauna, impactos sonoros, e grande quantidade de lixo sendo despejado sem nenhum controle e / ou fiscalização. O local é utilizado como lixão, sem qualquer estudo de impacto ambiental, controle, fiscalização ou acompanhamento profissional (Figura 6d). Por fim, no afloramento (26) Rodovia BR 050, a falta de vegetação, inscrições em rochas, lixos, impactos sonoros e riscos associados à saúde (ferimento fatal) foram os impactos observados.

Neste sentido, os afloramentos (2) Ponto 1 de Price, (3) Ponto 2 de Price, (6) Cachoeira de Ponte Alta, (13) Avenida Randolfo Borges Júnior, (17) Córrego da Saudade, (20) Pedreira de Léia e (26) Rodovia BR 050, devem ter a identificação das causas prováveis dos impactos (fase 6) e estratégias de manejo (fase 7), segundo o método Visual Impact Managmente - VIM. Após a realização destas etapas (fases $6 \mathrm{e} 7$ ), estes pontos devem ser monitorados (fase 8). Para os demais atrativos descritos e analisados, a fase de monitoramento ambiental (geoconservação) deveria estar sendo realizada, proporcionando um controle eficaz dos recursos naturais utilizados como atrativos geoturísticos (geodiversidade). 
Potencial Geoparque de Uberaba (MG): geodiversidade e geoconservação

Letícia Hirata Godoy, Diego de Souza Sardinha, Reinaldo José Bertini, Fabiano Tomazini da Conceição, Carolina Del Roveri, César Augusto Moreira

Figura 6. Pontos analisados pelo índice de analise ambiental simplificado, que apresentaram impacto muito alto. a) Ponto 1 do Price (2). b) Ponto 2 do Price (3). c) Avenida Randolfo Borges Júnior (13). d) Pedreira de Léia (20).
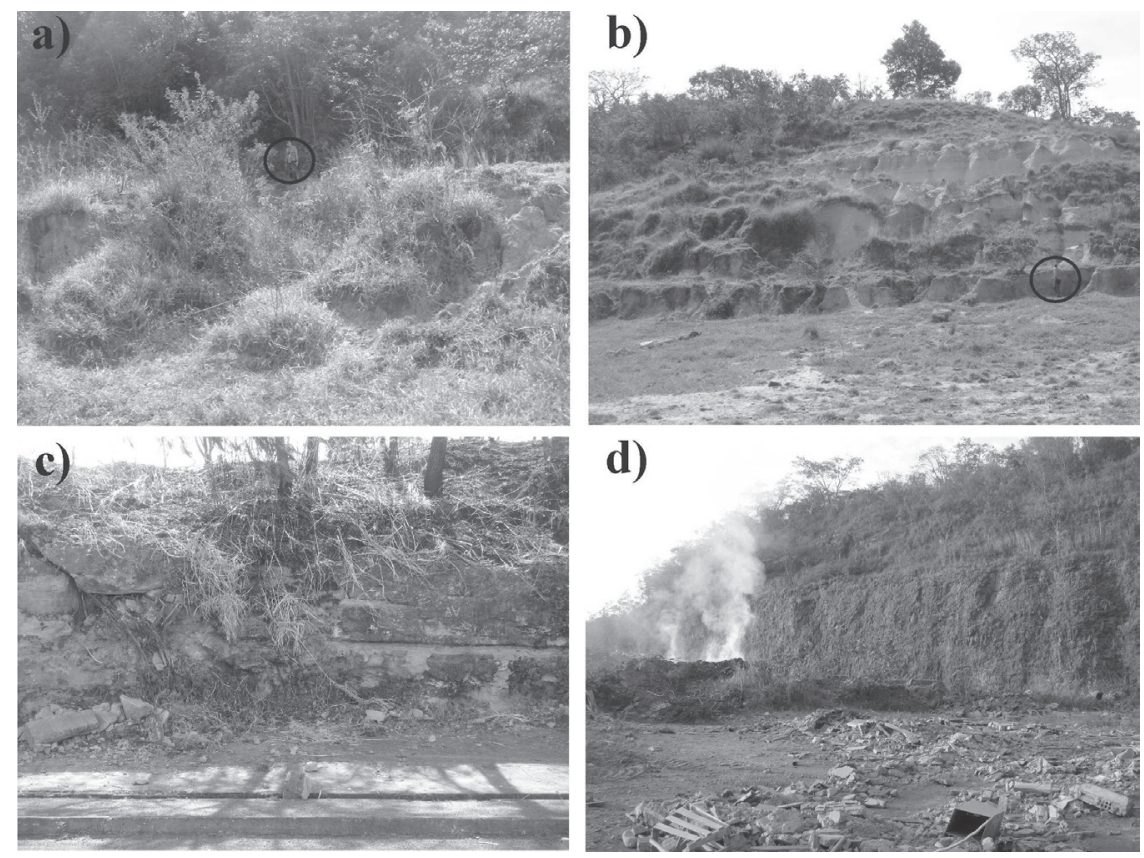

Fonte: Trabalho de campo. Fotos dos autores.

Utilizando-se o modelo de Pressão-Estado-Resposta (OECD, 1994), também é possível identificar algumas estratégias de manejo, fiscalização e controle para os locais analisados, que possuem presença muito alta de impacto ambiental (Quadro 3). Estes potenciais atrativos geoturísticos possuem distintos impactos ambientais, devido aos diferentes tipos de usos e ocupações do solo em cada região. Os afloramentos (2) e (3), pontos 1 e 2 de Price, estão localizados em uma área rural, onde há um grande desmatamento e desmonte de rochas para a prospecção paleontológica, sendo os indicadores biofísicos mais afetados falta da cobertura vegetal e fauna, grandes processos de erosão e impactos sonoros, por conta da utilização de britadeira. Em relação aos indicadores biofísicos mais afetados no afloramento (17) Córrego da Saudade, e (20) Pedreira de Léia, destacam-se o lançamento de resíduos sólidos e efluentes líquidos, perda de biodiversidade e cobertura vegetal, sendo todos estes impactos oriundos da área urbana de Uberaba.

Todos estes impactos poderiam ser corrigidos por uma administração pública mais eficiente em relação à gestão ambiental municipal. Assim algumas medidas de manejo, controle e fiscalização poderiam ser adotadas para reduzir estes impactos nas áreas rurais ou urbanas, tais como os propostos por Sardinha et al. (2010):

I - cumprimento da legislação para a conservação de APPs, áreas de preservação permanente;

II - recuperação de áreas degradadas;

III - controle e planejamento das expansões urbana e rural;

IV - estrutura adequada de prestação de serviços e sinalização;

V - coleta e disposição adequada dos resíduos sólidos;

VI - sistema de tratamento de efluentes;

VII - criação de mecanismos para facilitar a interlocução do poder público com a sociedade, melhorando colaboração entre os órgãos governamentais e produtores rurais;

VIII - capacitar mão de obra qualificada;

IX - aplicar técnicas de uso e conservação do solo;

X - fomentar atividades florestais sustentáveis; XI - ação participativa com universidades. 
Potencial Geoparque de Uberaba (MG): geodiversidade e geoconservação Letícia Hirata Godoy, Diego de Souza Sardinha, Reinaldo José Bertini, Fabiano Tomazini da Conceição, Carolina Del Roveri, César

Augusto Moreira

Quadro 3. Sugestão de estratégias de manejo elaboradas em função dos impactos detectados e suas causas prováveis. Modificado de SARDINHA et al. (2007).

\begin{tabular}{|c|c|c|}
\hline Pressão & Estado & Resposta \\
\hline Desmatamento & $\begin{array}{c}\text { Vegetação composta por gramíneas ou } \\
\text { ausentes }\end{array}$ & $\begin{array}{c}\text { Cumprimento legal e conservação das áreas de } \\
\text { APP's, recuperação das áreas degradadas, con- } \\
\text { trole e planejamento adequados à exploração } \\
\text { paleontológica }\end{array}$ \\
\hline $\begin{array}{c}\text { Perda da biodiver- } \\
\text { sidade }\end{array}$ & Pouca presença de animais nativos & Recuperação das áreas degradadas \\
\hline $\begin{array}{c}\text { Perda de solo e que- } \\
\text { da de blocos }\end{array}$ & $\begin{array}{c}\text { Erosão devido ao desmonte de rochas } \\
\text { e solos }\end{array}$ & $\begin{array}{c}\text { Recuperação das áreas degradadas, mão de } \\
\text { obra qualificada e utilização de equipamentos } \\
\text { adequados para exploração paleontológica }\end{array}$ \\
\hline $\begin{array}{c}\text { Acidentes leves até } \\
\text { fatalidades }\end{array}$ & Riscos de ferimento & $\begin{array}{c}\text { Estrutura adequada à prestação de serviços e } \\
\text { sinalização }\end{array}$ \\
\hline $\begin{array}{c}\text { Perturbação e dese- } \\
\text { quilíbrio do ecossis- } \\
\text { tema }\end{array}$ & Impactos significantes & $\begin{array}{c}\text { Estudo apropriado, revelando a capacidade do } \\
\text { meio em relação aos impactos sonoros }\end{array}$ \\
\hline $\begin{array}{c}\text { Danos no entorno e } \\
\text { poluição visual }\end{array}$ & Vandalismo no entorno & $\begin{array}{c}\text { Constantes fiscalizações, sinalização adequada } \\
\text { e restauração ambiental }\end{array}$ \\
\hline $\begin{array}{c}\text { Poluição do atrativo } \\
\text { Grande quantidade de lixo }\end{array}$ & $\begin{array}{c}\text { Estruturação e sinalização do local, coleta e } \\
\text { disposição adequada dos resíduos no Município } \\
\text { de Uberaba }\end{array}$ \\
\hline $\begin{array}{c}\text { Lançamento de } \\
\text { efluentes }\end{array}$ & Despejos “in natura” de esgoto & $\begin{array}{c}\text { Sistema de tratamento de efluentes adequado e } \\
\text { abrangente para o Município de Uberaba }\end{array}$ \\
\hline
\end{tabular}

Elaboração dos autores.

\section{CONSIDERAÇÕES FINAIS}

A diversidade e a importância dos atrativos geoturísticos (geodiversidade), a serem conservados como Patrimônio Natural, estão no testemunho científico dos acontecimentos que marcaram a história evolutiva do Planeta Terra, podendo ser utilizados para fins científicos, didáticos, culturais e geoturísticos, buscando uma nova modalidade de turismo na região, como alternativa econômica sustentável para o município.

A utilização do método Visitor Impact Management (VIM) contribuiu para a identificação dos principais impactos ambientais dos potenciais atrativos geoturísticos, integrando as informações referentes aos indicadores biofísicos de impactos ambientais e as sugestões quanto à conservação dos recursos naturais (geoconservação). Como visto no decorrer do trabalho alguns recursos naturais estão em acelerado processo de degradação ambiental, algo lamentável diante da relevância do patrimônio natural e geodiversificado de Uberaba.

Os impactos ambientais reconhecidos nos diversos pontos de interesse geoturístico resultam da falta de políticas de conscientização da população, aliadas a ausência de mecanismos eficientes de fiscalização e cumprimento da legislação vigente. Neste sentido, é de fundamental importância a gestão pública efetiva, com ênfase para questões de preservação ambiental e saneamento básico.

Nenhum atrativo alcançou pontuação suficiente para ser atribuída a classificação de mínima ou pouca presença de impacto, no entanto o atrativo que apresenta menor impacto dentre os pontos analisados 
trata-se da Cachoeira do Vale Encantado (Formação Marília), localizada na Reserva Particular do Patrimônio Natural Vale Encantado. Assim, além das propostas discutidas, é sugerida a criação de uma Unidade de Conservação no município, para que haja proteção dos recursos naturais e geocientíficos presentes.

\section{REFERÊNCIAS}

CAMINHOS GEOLÓGICOS. Geoturismo: proposta do projeto Caminhos Geológicos. Disponível em: $<$ http://www.caminhosgeologicos.rj.gov.br>. Acesso em: 22 abr. 2012.

CAMOZZATO, E. \& SCHOBBENHAUS, C. 2003. Geologia de Unidades de Conservação e de Elementos Naturais Singulares - Projeto Geoparques: Considerações sobre Unidades Federais e Estratégias para Avaliação do Patrimônio Geológico Nacional pelo SGB. São Paulo: CPRM - DEGEO, 2003. 72 p.

CIFUENTES, M. A. Determinación de capacidad de carga turística en areas protegidas. Programa de $\mathrm{Ma}$ nejo Integrado de Recursos Naturales. Série Técnica, Informe Técnico. Centro Agronómico Tropical de Investigación y Enseñanza (CATIE), n. 194, 28 p., 1992.

CPRM. Companhia de Pesquisa de Recursos Minerais. Llewellyn I. Price. Disponível em: $<\mathrm{http}: / /$ www.cprm.gov.br/publique/cgi/cgilua.exe/sys/start. htm?infoid=526\&sid=8>. Acesso em: 20 ago. 2012.

FERNANDES, L. A.; COIMBRA, A. M. Revisão estratigráfica da parte Oriental da Bacia Bauru (Neocretáceo). Revista Brasileira de Geociências, v. 30, n. 4, p. 717-728, 2000.

FREIXEIDAS-VIEIRA, M. V.; PASSOLD, A. J.; MAGRO, T. C. Impactos do uso público: um guia de campo para utilização do método VIM. In: II CONGRESSO BRASILEIRO DE UNIDADES DE CONSERVAÇÃO, 2, 2000, Campo Grande. Anais... Campo Grande, 2000. v. 2, p. 296 - 305.

GRAEFE, A. R.; KUSS, F. R.; VASKE, J. J. Visitor Impact Management. The Planning Framework.
Washington, n. 2, 105p, 1990.

HASUI, Y. A Formação Uberaba. In: $22^{\circ} \mathrm{CON}-$ GRESSO BRASILEIRO DE GEOLOGIA, 1968, Belo Horizonte. Anais... Belo Horizonte, SBG, 1968, p. $167-179$.

IBGE. (Instituto Brasileiro de Geografia e Estatística). Banco de dados: o Brasil município por município. Disponível em: <http://www.ibge.gov.br/cidades>. Acesso em: 07 maio 2011.

MACHADO, M. F.; SILVA, S. F. Geodiversidade do Estado de Minas Gerais. Belo Horizonte: CPRM, 2010. $131 \mathrm{p}$.

MAGRO, T. C. Impactos do uso público em uma trilha no planalto do Parque Nacional do Itatiaia. 1999. 135 f. Tese (Doutorado) - Curso de Ciências da Engenharia Ambiental, Escola de Engenharia de São Carlos, USP, São Carlos, 1999.

MAGRO, T. C. Impactos ambientais de projetos de turismo rural. In: CONGRESSO BRASILEIRO DE TURISMO RURAL, 2001, Piracicaba. In: OLIVEIRA, C. G. S.; MOURA, J. C.; SGAI, M. (Eds.) Turismo no espaço rural brasileiro. Piracicaba: FEALQ, 2001. v. 1, p. $75-89$.

NASCIMENTO, M. A. L.; AZEVEDO, U. R.; NETO, V. M. Geoturismo: um novo segmento do turismo. PUC Minas - Revista de Turismo, v. 2, n. 3, 12 p., 2007.

NPS. (National Park Service. U.S. Department of the Interior). The Visitor Experience and Resource Protection (VERP), Framework A Handbook for Planners and Managers. Arches National Park: Denver Service Center, 1997, $103 \mathrm{p}$.

OECD. Organization for Economic Co-Operation and Development. OECD core set of indicators for environmental performance reviews: A synthesis report by the Group on the State of the Environment. 93. Paris: OCDE / GD, 1994, p. 39 - 179.

PMU (Prefeitura Municipal de Uberaba). Uberaba 
em dados: Capítulo 01 - caracterização. Uberaba: Secretaria Municipal de Desenvolvimento Econômico e Turismo, 2009. $21 \mathrm{p}$.

RADAMBRASIL. Folha SE 22. Goiânia. Rio de Janeiro: Ministério de Minas e Energia, Projeto RadamBrasil, 1983. (Levantamento de recursos naturais, 31).

ROCHA, J. C. A. D.; NASCIMENTO, M.A. L. O Pico do Cabugi como produto ecoturístico e geoturístico no Rio Grande do Norte. Revista Global Tourism, v. 3, n. 2, 22 p., 2007.

SARDINHA, D. S.; CONCEIÇÃO, F. T.; CARVALHO, D. F.; CUNHA, R.; SOUZA, A. D. G. Impactos do uso público em atrativos turísticos naturais do Município de Altinópolis (SP). Geociências, v. 26, n. 2, p. 161-172, 2007.

SARDINHA, D. S.; CONCEIÇÃO, F. T.; GODOY, L. H. Índice simplificado na avaliação de impacto ambiental nos recursos hídricos da bacia hidrográfica do Ribeirão do Meio, Leme, São Paulo, Brasil. Augmdomus, n. 2, p. 82-97, 2010.

SILVA, J. R. B.; PERINOTTO J. A. J. O geoturismo na geodiversidade de Paraguaçu Paulista como modelo de geoconservação das estâncias. Revista Global Tourism, v. 3, n. 2, 40 p., 2007.

SOARES, P. C.; LANDIM, P. M. B. Aspectos da estratigrafia da Bacia do Paraná no seu flanco nordeste. In: XXVII CONGRESSO BRASILEIRO DE GEOLOGIA, Porto Alegre, 1974. Anais... v. 01, p. 243-256, Porto Alegre, 1974.

SOARES, P. C.; LANDIM, P. M. B.; FULFARO, V. J.; SOBREIRO NETO, A. F. Ensaio de caracterização estratigráfica do Cretáceo no Estado de São Paulo: Grupo Bauru. Revista Brasileira Geociências, v. 10, n. 3, p. 177-185, 1980.

SQUISATO, E.; NARDY, A. J. R.; MACHADO, F. B.; MARQUES, L. S.; ROCHA JR, E. R. V.; OLIVEIRA, M.A. F. Litogeoquímica e aspectos petrogenéticos dos basaltos da Província Magmática do Paraná na porção
Centro-Norte do Estado de São Paulo. São Paulo. Geociências, v. 28, n. 1, p. 27-41, 2009.

STANKEY, G. H.; COLE, D. N.; LUCAS, R. C.; PETERSEN, M. E.; FRISSEL, S. S. The limits of Acceptable Change System for wilderness Planning: General Technical Report INT. United States Department of Agriculture, 1985, p. 137-176.

UNESCO. International Network of GEOPARKS. (2005). Disponível em: <http://www.unesco.org/ science/earthsciences/geoparks/geoparks.htm>. Acesso em: 20 abr. 2012.

VALE JUNIOR, R. F. Diagnóstico de áreas de risco de erosão e conflito de uso dos solos na bacia do rio Uberaba. 2008. 222 f. Tese (Doutorado) - Curso de Produção Vegetal, Faculdade de Ciências Agrárias e Veterinárias, Unesp, Jaboticabal, 2008.

VIANA, F. C.; NASCIMENTO, M. A. L. O turismo de natureza como atrativo turístico do Município de Portalegre, Rio Grande do Norte. Campinas: SeTur/ SBE. Pesquisas em Turismo e Paisagens Cársticas, v. 2, n. 1, p. 79-96, 2009.

WEARING, S.; NEIL, J. Ecoturismo: impactos, potencialidades e possibilidades. São Paulo: Manole, 2001, 256p.

ZANFELICE, T.; ETCHEBEHERE, M. L.; SAAD, A. R. Avaliação preliminar do potencial turístico do Município de Rifaina (SP) e os impactos decorrentes do uso público de seus atrativos paisagísticos. Geociências, v. 28, n. 2, 2009, p. 203-220. 